Journal of Teacher Education for Sustainability, vol. 19, no. 2, pp. 21-35, 2017

\title{
Addressing Cultural Identity through Negotiation: Analysis of Student-teacher-authored Narratives
}

\author{
Naser Rashidi and Hussein Meihami \\ Shiraz University, Shiraz, Iran
}

\begin{abstract}
Teachers' cultural identity is among the forepart issues within the realm of teacher education studies. The research about teachers' identity has been done using teacherauthored narratives. That said, the purpose of this study was to investigate the role of negotiation in the student-teachers' cultural identity formation. To that end, three studentteachers (two males and one female student-teachers), majoring in English language teaching participated in this study. During four months, the student-teachers participated in a negotiation program on cultural identity. They were sent some academic papers to study, then, they participated in discussions about cultural variations and the ways to address them in classrooms. The student-teachers where asked to write their narratives. Then the narratives where analyzed based on the semantic expressions. The qualitative analysis of the student-teachers' narratives showed that their cultural identity changed during the negotiation period. By analyzing the student teacher-authored narratives, it appeared that they addressed cultural variations in different ways includingusing cultural varieties in teaching, identifying the gaps between cultural contexts, reconceptualization of cultural concepts, cultural transformation, new modes of using culture, internalization of cultural issues, and cultural awareness, each of which is discussed in the current study. It can be concluded from the obtained information that cultural identity is a dynamic one and open to change. The research bears some implications for teacher education policy makers to introduce sustainable teacher education program in general, and sustainable second language teacher education program in particular.
\end{abstract}

Keywords: sustainable teacher education, teacher-authored narrative, negotiation, student-teachers

\section{Introduction}

Language teacher identity is a vexing issue which cannot be considered as an innate attribute acquired once and for ever. However, the concept of language teacher identity is a co-constructed and socially driven issue which can be influenced by a number of factors. Teacher identity in general, and language teacher identity in particular, are in close relation with what teachers construct in their profession about the identity. According to Goh et al. (2005) teachers' sense about their profession can alter their 
motivation to play their role as a teacher in an arena of performances in which they negotiate many things with the surrounding factors. It is also possible that their identity changes the way they approach curricular and institutional principles. This leads to myriad studies (e.g., Chong, 2011; Chong, Low, \& Goh, 2011; Meijer, de Graaf, \& Meirink, 2011) on the issue of teacher identity which in its place is due to the shift in the perspective toward the teachers' role.

Identity can be in direct relationship with "being" and "doing" (McNaughton \& Billot, 2016). Being means that how a person, or in our case a teacher, views the world based on the attitudes, assumptions, beliefs, and values that person possesses. Doing is related the influence of the mentioned factors in the way that a person lives (Taylor, 1989). Korhonen and Törmä (2016) believe that the teacher being and doing which createhis/her dynamic identity has an utmost importance in the professional growth of the teacher. Jawitz (2009) declares that through expressing the being and doing teachers can join into different communities of practice. That said, one may refer to the academic identity of teachers as the conceptualization of doing and being of teachers' stances based on the values and ideology in a community of practice (De Fina 2009; McNaughton \&Billot, 2016).

Closely related to the being and doing of teacher education is what Kumaravadivelu (2012) states about teacher identity. According to Kumaravadivelu (2012) the teaching behavior of a teacher is in direct relationship to what he/she possesses as identity about the world. Given that, the desired teaching can be achieved if we can understand the perceptions of teachers about the world. Teachers are in direct relation to various social, cultural, and political constructs in their society which leads them to establish a set of identity outputs. The identity of a teacher can affect the way he/she teaches. Teachers' identity is only one aspect of the other parts of teaching Self, including teacher beliefs and teacher values. These factors can be investigated for the purpose of sustainable teacher education. It is, hence, related to the concept of sustainable education in general, and sustainable teacher education in particular (Raus, 2016). The field of sustainable teacher education is considered as a new but important issue which scholars need to pay more attention (Stanszus et al., 2017).

Identity has been defined in many different angles due to the subjective nature it has. The field anthropology has witnessed the scholars of different fields such as philosophy, theology, and sociology provide different definitions for identity. Elliott (2009) states that identity "has proved to be one of the most vexing and vexed topics in the social sciences and humanities." (p. viii). Consequently, the term identity can be defined differently if one sticks to the very categorization of modernism and postmodernism. The two schools struggle on whether identity is unified, multiple, singular, and bounded or not. In the next section, we will approach identity of the teachers from a theoretical perspective.

\section{A Dialogic Response Toward Teacher Identity}

In the course of literature analysis, it appears that identity is a complex and manyfaceted theoretical concept (Alsup, 2006; Gee, 2001). In direct relation to the concepts of being and doing, Holland et al. (1998, p. 5) point out that "identities, the imaginations of self in worlds of action, ... lived in and through activity and so must be conceptualized as they develop in social practice." That is the emergence of "becoming". Teachers' 
identity has a process from being to doing in which the final result will be becoming. Given that, it is believed that each and every teacher's identity theorized in a reciprocal relationship with others' identity. Bakhtin (1990) asserts that the understanding of the relationship between one's "self" and "others" will lead to the understanding of teacher identity. Having the conceptualization of Bakhtinin mind, a dialogic approach is necessary to identify the relationshipbetween one's "self" and "others" (Hallman, 2015). Using a dialogic approach in this way helps to construct a two-way response toward the intentions of others and the responses of self. It is worth mentioning that one of the principles of dialogism is that each and every language which is produced is the response to the language of others (Hallman, 2015). According to Bakhtin (1990) the language can also be a text. This means that the texts which are produced by the teachers can also be regarded as the manifest of teachers' identity.

Based on what have been said about identity, self, and others, it can be concluded that negotiation on different issues in teacher professional development can have effect on a teacher's identity. Consequently, rising the awareness of teachers about various matters in the teacher education program can be framed with what Bakhtin believed as the relationship between self and others. It is also a reminder of what Vygotsky (1979) states that through others we become ourselves. Moreover, as Kumaravadivelu (2012) states self can be negotiated constantly. This can be "the result of individuals' continual critical engagement with others who share their personal and professional space." (Kumaravadivelu, 2012; p. 59). Hence, negotiation can be a catalyst of identity. The identity of a teacher is negotiable due to the fact that, as Jenkins (1996) and Vygotsky (1986) declare, it is a socially constructed and socially shared notion. In this regard Jenkins (1996, p. 3) states that

\section{if only because identities are about meaning, and meaning is not an essential property of words and things. Meanings are always the outcome of agreement or disagreement, always a matter of convention and innovation, always to some extent shared, always to some extent negotiable.}

Through the analysis of the quotation, this is well-illustrated that the identity formation and to some extent changing can be achieved through the negotiation. It is an undeniable fact that social realities such as ethnic, religion, and linguistic differences might have an effect on the identity of the teachers. Sen (2006) calls that multiple monoculturalism; in which each society with different and distinct culture tries to preserve its own identity. This may lead to the ignorance of differences in the society by the teachers. It is clear from the above lines that teachers' identity is transferable to the classroom. It is also important to know that identity of the teachers is a notion which is socially constructed. Consequently, many other different factors which are to some great extent socially constructed are involved (Jenkins, 1996). Hence, it is correct to say the negotiation between Self and those factors may change the identity of the teachers. Thus, the purpose of this study was to investigate the effects of raising teachers' awareness about cultural variations through negotiation on their identity change. That said, through different terms of conditions, we conducted various discussions on the mentioned topics and investigated the cultural identity of the teachers through the narration they produced. To that end, the following research question is addressed:

1. How do teachers' identity change when their awareness will be raised about social and cultural variations in the society? 


\section{Literature Review}

The historical perspectives toward the notion of identity date back to the $20^{\text {th }}$ century when the researchers and theorists in different fields of study started to pay attention to this notion (Martel \& Wang, 2015). The notion of identity has been scrutinized by Holland and Lachicotte (2007); leading them to two mainstreams of theorizing: a psychological idea by Erick Erikson and a sociological one by Goerge Mead. Given that, Holland and Lachicotte (2007, p. 107) stated that

An Eriksonian 'identity' is overarching. It weaves together an individual's answers to questions about who he or she is as a member of the cultural and social group(s) that make up his or her society. A Meadian identity, on the other hand, is a sense of oneself as a participant in the social roles and positions defined by a specific, historically constituted set of social activities.

The notion of identity first appeared in language pedagogy with regard to the language learners. Norton (2000) conducted a study on the immigrant women learning English in Canada. In this study, Norton investigated how identity was considered with regard to the context of teaching and learning. It was approximately at the end of 1990s when researchers in the field of teacher education started to consider teacher identity as the subjects of their studies (Martel \& Wang, 2015). Some pioneer studies such as the one by Duff and Uchida (1997) and Antonek, McCormick, and Donato (1997) are the prime examples. Scrutinizing the literature, it can be stated that most of the empirical studies on language teacher identity are focusing on native and non-native speaking teacher identity (Menard-Warwick, 2008). Later on, researchers (e.g., Fichtner \& Chapman, 2011; Menard-Warwick, 2011) conducted studies addressing language teachers' cultural identity.

By reviewing the studies conducted within the realm of language teacher education, one can reach the major themes. Miller (2009; p. 178) believed that the notion of identity should be explicitly taught to the student-teachers to raise their critical reflection that "takes account of identity and related issues, of individuals in specific contexts, and of the role of discourse in shaping experience." Different investigations were done to see the significant role of others in the teachers' identity formation (Martel \& Wang, 2015). It is believed that those whose roles are significant in the teachers' identity formation are "mentor teachers, classmates, and teacher educators, while in the workforce, significant others include colleagues, administrators, and students." (Martel \& Wang, 2015; p. 290). The influence of the above mentioned "others" on language teachers' identity has been referred to in some studies such as the one Liu and Xu (2011) and Park (2012). For instance, Park (2012) investigated the status of non-native studentteachers in the United States where some of the student-teachers last their confidence due to the questions by the language learners about their ability in teaching English to the natives.

Moreover, the prior experiences and the personal biography that teachers possess may form their identity (Duff \& Uchida 1997; Izadinia 2013). In the study by Duff and Uchida (1997), it was revealed that some of the teachers did not use the textbooks in their classroom while they taught grammar due to the experiences they had in their school time. Furthermore, in the study by Yi (2009) it was revealed that prior experience was a determining factor in language teacher's identity. Ennser-Kananen and Wang's 
(2013) study, moreover, showed that the participants expressed regret over the interactions with other cultures leading to weaken their first language cultural identity.

The researchers (Morgan \& Clarke, 2011) believed that one more issue which is important in language teacher identity formation is the context. There are two contexts which the student-teachers do their activities: the teacher education program and the schools where they teach. Feiman-Nemser and Buchmann (1985) called this as the "the two world pitfall". In some of the studies such as the one by Luebbers (2010), the student-teachers were complaining about the reality of classrooms. To put it in another way, student-teachers' professional development is done within the context of teacher education; in which some of the realities are ignored with regard to the student-teaching contexts. This problem is not specific to the teacher education program and studentteaching contexts, but it can also be seen during the first years of instructions by the teachers (Zeichner \& Tabachnik, 1981). This may lead to the change in their identity.

Although cultural issues are integrated with language teaching and teacher identity, there are not many investigations in this regard. Researchers (e.g., Ennser-Kananen \& Wang 2013; Fichtner \& Chapman 2011; Menard-Warwick, 2011) asserted that intercultural issues helped not only to the formation of teacher identity regarding different cultures but also it helped to approach teaching culture. According to Martel and Wang (2015, p. 293) "tensions and struggles are common themes in the construction of language teachers' bi- or multi-cultural identities." In a study conducted by Fichtner and Chapman (2011) it was revealed that there was disequilibrium in the teachers' identity while they formed their first and second identity with regard to the language they learnt to teach later. The student-teachers in Fichtner and Chapman's study had declared that their primary identity was in association to their national identity, whereas the second identity, which was difficult for them to come up with, was regarded as the target language culture. Moreover, in the study conducted by Ennser-Kananen and Wang (2013), it was revealed that the more the teachers' intercultural experiences were, the more their tendency toward teaching culture.

More often than not, the studies conducted to investigate the cultural issues and teachers' identity showed that teachers often relied on their own cross-cultural and cultural experiences to teach culture in their classes (Duff \& Uchida, 1997). That said, Morgan (2004) called the phenomenon as "identity as pedagogy" in which "the teacher's identities are performed in classroom conversations around culture and, in turn, transformed in the culture teaching practice." (Martel \& Wang, 2015; p. 293).

\section{Methodology}

\section{Teacher-authored Narratives}

In this study we were investigating the role of negotiation of cultural variations on student-teachers' cultural identity formation. To that end, we used teacher-authored narratives as the source of data. From 1990s, narratology has been introduced as an approach to understand and document the professional development of the teachers (Carter, 1993; Doyle, 1997). According to Johnson (2007) "narrative inquiry, as a form of professional development, represents systematic self-exploration conducted by teachers through their own stories and language" (p. 175). Through using narratives one can understand the complexities a teacher may face, and trace the professional development 
trend of a teacher. As Johnson and Golombek (2002) point out narrative inquiry can help teachers to self-understand themselves, so it can lead them to change; change in identity for instance.

In the current study, we went through the narrative epistemology (Bruner,1996) and the argument that narratives are the manifest of the constructive process based on which human beings interoperate their activities and experiences (Sarbin, 1986). According to Johnson (2007, p. 178) “This stance recognizes that narratives, by their very nature, are not meant to describe phenomena objectively, but rather to expose how people's understandings of phenomena are infused with interpretation." It can be concluded that narratives are socially mediated and cannot be reduced except if they lose their essence (Clandinin\& Connelly, 2000; Lyons \&LaBoskey, 2002). It is also worth mentioning that narratives are chronological regarding different events at focus. Through the reconstruction of the stories teachers show their stance with the issues. According to Johnson (2007), due to the transformative power of narratives as a manifest of systematic change they "become a mainstay in teacher education Programs" (p. 179).

\section{Teacher Narratives Collection and Analysis Method}

In our study, we scrutinized the narratives of three student-teachers regarding their cultural identity before and after negotiations. Given that, we used ethnographic semantics (Spradley, 1979) to analyze the narratives by focusing on the meanings the teachers provided to their verbal expressions. In this study, in order for more accuracy and more analysis we have used MAXQDA software which helped us to delve into the narratives deeply.

During the four months, the lead researcher negotiated with the three studentteachers about their cultural identity. Before the negotiation the lead researcher asked the student-teachers about their stance with regard to the cultural issues in the classrooms. This included many factors such as the importance of teaching cultural issues, how they reacted toward different cultures, and how they approach students' culture which were something other than the main culture of the class. The student-teachers wrote their narratives and delivered them to the researchers.

In the second phase of the study, the lead researcher started to negotiate on studentteachers' cultural identity by using different methods. First of all, the lead researcher sent some related academic papers whose subjects were about the above mentioned issues. The student-teachers were asked to study them. Then the lead researcher started to negotiate on different notions and terms with the student-teachers. In this way, the student-teachers' cultural identity were negotiated.

One more instructional tool was the short clips on cultural issues in the L2 classrooms which were sent to the student-teachers and they were asked to watch them and, later, discuss them with the lead researcher. Approximately, each and every week the lead researcher negotiated the cultural issues regarding the cultural identities of the studentteachers.

At the end of the four months, the researchers asked the student-teachers to write another narratives regarding cultural issues and the way they might consider the differences in cultural issues in their classrooms. Then after, the narratives produced by the student-teachers during the program were categorized in different excerpts and were analyzed using MAXQDA software. The software helped us to obtain the main themes 
of the narratives written by the student-teachers and the relationships among the themes. To analyze the obtained information from the interviews, the researchers used Strauss and Corbin's (1998) systemic approach. Grounded theory studies can be codified and described through using the systemic approach. There are three coding levels in systemic approach including open coding, axial coding, and selective coding. The researcher started to analyze the interviews by open coding. In this level of coding the major or core, categories were specified. The next level is axial coding in which the categories will be broken into subcategories and sub-themes. Finally, in the selective coding the researcher developed propositions and hypotheses based on the model; showing the related categories. MAXQDA helped to do the analysis more systematically.

\section{Results}

To obtain the information about the role of negotiation on the cultural identity of the student-teachers we, as stated earlier, used the narratives produced by the three student-teachers. Firstly, we obtained the main themes which the student-teachers mentioned and the qualitative extent to which they have discussed them. Figure 1 shows the information.

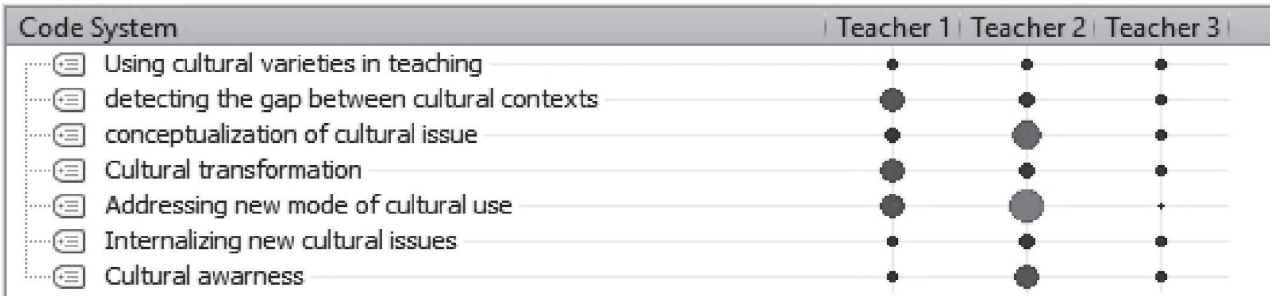

Figure 1. Main themes student-teachers addressed about cultural variations in their narratives

As can be seen in Figure 1, there are seven main themes that we identified in the narratives written by the student-teachers regarding the change in their cultural identities after the negotiations. Qualitatively, the most referred theme was addressing new mode of cultural use by teacher \#2. Then conceptualization of cultural issue and cultural awareness by Teacher \#2 and detecting the gap between cultural contexts, cultural transformation, and addressing a new mode of cultural use by Teacher \#1 were the most referred themes in the narrations. Teacher \#3 also referred to the mentioned themes. In the following lines of inquires we mention some excerpts by the student-teachers with regard to using cultural varieties in teaching. The sections referring to the negotiations and cultural identities of the student-teachers have been become bold.

Excerpt \#1: Using cultural varieties in teaching

Teacher \#1: ... after a while and when I read some papers on the opportunities of cultural varieties in teaching I came to the conclusion that some of the cultural differences I observed in my classes that my students can help me in expanding the cultural subjects in the class...

Teacher \#2: Reading about cultural varieties was important for me in two ways. First, I changed my strict view with regard to the best culture for the classroom. Pre- 
viously, I had the idea that not all cultures could be taught in the classrooms. Now that I studies more on the role of culture and cultural differences in the classrooms I change this view. Moreover, it can help us to teach different skills in the classroom based on cultural differences ...

Teacher \#3: I think one of the advantages of cultural differences is to change the view of the students about the idea that their culture is the best. Through thinking about the differences, both teachers and learners can raise their understanding about the environment around themselves.

The second theme which we extracted from the narratives of the teachers was detecting the gap between the cultural contexts. It is worth defining contexts here. Each and every person has got his/her own context which determines some limitations for them. That said, the more the context of a teacher will be similar to that of his/her students, more opportunities for learning can be achieved. The gap between the cultural context of a teacher and his/her students may lead to complex issues in the classroom. In the following excerpt we address how the student-teachers refer to this issue after they did the negotiation.

Excerpt \#2: Detecting the gaps between cultural contexts

Teacher \#1. In a discussion I had with some of the colleagues about the cultural varieties I come to understanding that each teacher has his/her own context of performance which needs to be as similar as it is possible ....

Teacher \#2. ... I do not say that without knowing about the cultural environment one cannot teach well; however, if we detect the gaps existing between the cultural values which are important for the teacher and the ones by the students, teaching will be flourished.

Teacher \#3. ... the paper I read changed my view with regard to detecting and bridging the cultural gaps... I think when I finish my student teaching and become a teacher in the first session of each class I will go through the cultural differences ...

Through the course of analysis, the student-teachers stated that while they negotiated the cultural issues they conceptualized cultural issues in new ways. The narrative written by the student-teachers showed that both the papers they read and discussions they had were influential in creating such cultural reconceptualization.

Excerpt \#3: Reconceptualization of cultural issues

Teacher \#1. When we discussed cultural issues new aspects about the essence of culture appeared. This leads to think about how I can use and react toward cultural issues in the classroom.

Teacher \#2. ... and by reading all those papers,the concept of why culture and cultural values should be implemented in the classroom has changed for me. I think I will have a wider cultural knowledge which helps me to think about culture not like the previous time.

Teacher \#3.... at the end of the discussions and reading materials, I draw conclusion that the new world has new culture so should it be for the classrooms ...

Cultural transformation was another theme which the student-teacher paid attention in the narratives they wrote. Through analyzing the narratives, we understood that by this theme, cultural transformation, the student-teachers meant that they could not only 
teach culture but also prepare an instructional environment that the students changed them based on the cultural values and beliefs they had. This could be done in a dialogic interaction between the teachers and the students.

\section{Excerpt \#4: Cultural transformation}

Teacher \#1. I do agree with the fact that classroom is like an arena for cultural transformation. Here is the place where teachers and students can be along each other to reach cultural agreement on the subjects which are shaky.

Teacher \#2. Through the potentials we have in our classrooms, I mean the students who are the main cultural potentials, we can learn new cultural issues and thank about them to transform them. I think the same phenomenon can happen for the students ...

Teacher \#3. ... I remember in one of the papers I studied the teacher's discussion lead to the cultural discussions in the classrooms in which they discuss every bits of the issue. I will tend to increase such discussions in my classroom.

The fifth them which the student-teachers addressed in their narratives was addressing new modes of cultural use. The theme means that how it is possible to use new mode in teaching cultural issue.

Excerpt \#5: Addressing new modes of cultural use

Teacher \#1. [in the discussions] it is now much easier to address cultural aspects in our teaching, since we have more facilities which can use to do cross-cultural comparisons ... I will use the internet in order to push my students to be familiar with cultural differences...

Teacher \#2. The information I obtained during the discussions convinced me to use new methods and facilities to teach culture in my classroom. The thing is, according to the conclusions of some of our discussions, we can now use various mode of teaching culture which make it both interesting and easy to teach.

Teacher \#3. ... I can say I will use new facilities to address teaching culture .... This is the recent discussion in the field of language teaching ... no one should be left behind from teaching cultural values and beliefs ... students can also use new modes to raise others about their culture ... I accept such proposals for my classroom by students of various culture to present their culture to others ...

Internalizing new cultural concepts is another theme which the student-teachers addressed in their narratives. Overall, their cultural identity about the variations changed, showing that the negotiations led them to pay more attention to cultural variations. The narratives also showed that the student-teachers would like to address internalizing new cultural concepts through new methods.

Excerpt \#6: Internalizing new cultural concepts

Teacher \#1.... my studying about teaching culture change my view that new cultural concepts should be internalized. The internalization, according to Vygotsky, is done by others. Consequently, in the new future I will go through internalizing cultural concept using the appropriate methods.

Teacher \#2. Before teaching culture, I think teachers should work upon the internalizations of concepts. In our discussions we come to the conclusion that if we will be able to internalized the concepts, cultural variations can be called upon easier...

Teacher \#3.... and it is the internalization of culture which I think is more important than paying attention to other aspects of teaching culture ... 
The last theme which the student-teachers referred to after negotiation about cultural variations was cultural awareness. The student-teachers, overall, stated that the negotiations led them to be culturally aware.

Excerpt \#7: Cultural awareness

Teacher \#1. Through studying different papers, my awareness about cultural variations increased. Now, I know how to treat cultural variations in my classroom and I come to the conclusion that some of my reactions were not that much appropriate.

Teacher \#2. Cultural and, sometimes, cross-cultural awareness can be achieved through negotiation types such as the one we had during these months. Raising the cultural awareness of the students and ourselves is very important and in the later time I will do some awareness raising tasks ...

Teacher \#3. ... I will do awareness raising activates in the classroom in order to prepare the condition for the students to raise their awareness about the cultural facts ...

\section{Discussion}

In the current study we have investigated the cultural identity of student-teachers through teacher-authored narratives. Through the course of analysis on the teacherauthored narratives we found out that after the negotiation the cultural identity of the student-teachers changed; in that they changed the way they had reacted toward cultural variations. The main themes which the student-teachers referred were using cultural verities in teaching, identifying the gaps between cultural contexts, reconceptualization of cultural concepts, cultural transformation, new modes of using culture in teaching, internalization of cultural issues, and cultural awareness. Unlike the studies done by Fichtner and Chapman (2011), the findings of this study showed no tension or struggle in the cultural identity formation of the student-teachers. Some explanations can be made on the obtained results.

First of all, the results indicated that the student-teachers' cultural identity changed and they considered the cultural variations as the advantages for instructing English language in their classrooms. It is showing that the student-teachers passed the state of being and went through the state of becoming (Izadinia, 2013). This also shows that the identity of student-teachers is a dynamic one, meaning that by participating in negotiation program their cultural identity with regard to the cultural variations changed (Beijaard et al., 2004; Maclean \& White, 2007; Beauchamp \& Thomas, 2009).

Moreover, the main themes we mentioned above showed that student-teachers situated in a process of professional identity formation (Putnam \& Borko, 1997). In this process of professional identity formation student-teachers use the identity they obtained through the process in the instructional program. It is the thing Morgan (2004) called identity as pedagogy. Based on the narratives of the student-teachers in this study, it was clear that they wanted to change their procedures in approaching cultural variations in the classrooms. This can be rooted in the negotiations the student-teachers participated since their cultural identity awareness enhanced in myriad ways.

On top of this, the classroom practices are influenced by the cultural identity of the teachers (Martel \& Wang, 2015). This is well-shown in the student-teacher-authored narratives of this study since in their explanations their cultural identity change caused to decide to use the cultural variations in the classrooms for instructing materials. More- 
over, they thought of new modes of representing cultural variations in their classrooms which could be due to the change in their cultural identity.

The context in which student-teachers are working is also very important in shaping their professional identity in general and cultural identity in particular (Morgan and Clarke 2011). It should be stated that the student-teachers, in this study and as genereal, had two contexts of participation: their teacher education program and the school teaching context. Analyzing the narratives by the student-teachers in this study and their cultural identity changed indicated that not only the negotiation they participated helped them to change their idea about cultural variations but also, probably, the schooling context they school teach might push them to work upon their future carrier.

One more point about the main themes obtained through the analysis of teacherauthored narratives is the transformation and reconceptualization of cultural concepts and issues. By referring to the two mentioned themes the student-teachers wanted to discuss cultural issues to find new cultural identity in this regard. We believe that this is due to the nature of negotiation. Based on negotiation principles the participants will learn to negotiate things through their critical thinking. During the four months, we think that since this ability increased in the student-teachers they wanted to implement this ability in the form of transformation and reconceptualization of cultural concepts and issues in their classrooms.

\section{Conclusions}

According to Gaudelli and Ousley $(2009$, p. 934) "identity work is vital in whatever way it manifests and that it is up to reflective teacher educators to enact this focus in appropriate ways that are contextually bound." This direct quotation well-illustrates the importance of Identity in teacher education program. In this study, we investigated the cultural identity change of the student-teachers during a negotiation program. The results of qualitative analysis of student-teacher-authored narratives showed that the student-teachers' cultural identity changed during the negotiation program, thus the results support the hypothesis that teacher cultural identity is dynamic and open to change.

The qualitative analysis of the student-teacher-authored narratives showed that the student-teachers' cultural identity changed with regard to the main themes such as using cultural verities in teaching, identifying the gaps between cultural contexts, reconceptualization of cultural concepts, cultural transformation, new modes of using culture, internalization of cultural issues, and cultural awareness. The mentioned themes were all related to cultural issues showing that student-teachers paid more attention to such issues. To put it in a nutshell, the themes showed more relations to instructional aspects of teaching cultural issues. Hence, it is showing the importance of changing in cultural identity with regard to cultural instructions. Moreover, teacher education policy makers should know that the role of negotiation in cultural identity formation of the teachers open new horizons to future sustainable teacher education programs (Miedema \& Bertram-Troost, 2015). That said, teaching cultureby means of its different approaches need to be more emphasized in the teacher education programs (Egne, 2014).

Finally, it is worth mentioning that finding new approaches to work on the identity ofstudent-teachers is important for teacher education programs. Miller (2009), suggested some directions in this regard: "understanding the nature of identity; knowing the context 
in which student-teachers work; engaging student-teachers in critical reflection; and beginning with learners' needs" (Martel \& Wang, 2015, p. 297). Portfolio writing is another way to develop the identity of teachers (Antonek et al., 1997).

\section{References}

Alsup, J. (2006). Teacher identity discourses: Negotiating personal and professional spaces. Mahwah, N.J.: L. Erlbaum Associates.

Antonek, J. L., McCormick, D. E., \& Donato, R. (1997). The student teacher portfolio as autobiography: Developing a professional identity. The Modern Language Journal, $81(1), 15-27$.

Bakhtin, M.M. (1990). Art and Answerability and Edited by Michael Holquist and Vadim Liapunov. Translated by Vadim Liapunov and Kenneth Brostrom.

Beauchamp, C. \& Thomas, L. (2009) Understanding teacher identity: an overview of issues in the literature and implications for teacher education, Cambridge Journal of Education, 39(2), 175-189.

Beijaard, D., Meijer, P.C., \& Verloop, N. (2004) Reconsidering research on teachers' professional identity, Teaching and Teacher Education, 20, 107-128.

Bruner, J. (1996) The narrative construal of reality. Boston: Harvard University Press.

Carter, K. (1993) The place of story in the study of teaching and teacher education, Educational Researcher, 22(1), 5-12.

Chong, S. (2011). Development of teachers' professional identities: from pre-service to their first year as novice teachers. KEDI Journal of Educational Policy, 8(2), 219_ 233.

Chong, S., Low, E. L., \& Goh, K. C. (2011). Emerging professional teacher identity of pre-service teachers. Australian Journal of Teacher Education, 36(8), 50-64.

Clandinin, D. J., \& Connelly, F. M. (2000) Narrative inquiry: Experience and story in qualitative research. San Francisco: Jossey-Bass.

De Fina, A. (2009). Group identity, narrative and self-representations. In A. De Fina, D. Schiffrin, \& M. Bamberg (Eds), Discourse and identity (pp. 351-375), Amsterdam: John Benjamins.

Doyle, W. (1997) Heard any really good stories lately? A critique of the critics of narrative in educational research, Teaching and Teacher Education, 13(1), 93-99.

Duff, P. A., \& Uchida, Y. (1997). The negotiation of teachers' sociocultural identities and practices in postsecondary EFL classrooms. TESOL Quarterly, 31(3), 451-486.

Elliott, A. (2009). Series editor's foreword. In H. Ferguson (Ed.), Self-identity and everyday life ( $\mathrm{pp}$. vii-x), New York: Routledge.

Ennser-Kananen, J., \& Wang, F. (2013, May-June). I am combined: Chinese teachers constructing their identities as culture teachers. Paper session presented at the Seventh International Conference on Language Teacher Education, Washington, DC.

Feiman-Nemser, S., \& Buchmann, M. (1985). Pitfalls of experience in teacher preparation. Teacher College Board, 87(1), 49-65.

Fichtner, F., \& Chapman, K. (2011). The cultural identities of foreign language teachers. L2 Journal, 3(1), 116-140.

Gaudelli, W., \& Ousley, D. (2009). From clothing to skin: Identity work of student teachers in culminating field experiences. Teaching and Teacher Education, 25(6), 931-939. 
Gee, J. P. (2001). Identity as an analytic lens for research in education. Review of Research in Education, 25, 99-125.

Goh, C. C. M., Zhang, L. J., Ng, C. H., \& Koh, G. H. (2005). Knowledge, beliefs and syllabus implementation: A study of English language teachers in Singapore. Graduate Programmes and Research Office, National Institute of Education, Nanyang Technological University.

Hallman, H., \& Burdick, M. (April, 2015). Community-based field experiences in teacher education: Examining the intersection of content-area learning with community based spaces. Paper presented at the annual meeting of the American Educational Research Association, Chicago, IL.

Holland, D., William L. Debra, S., \& Carole, C. (1998). Identity and agency in cultural worlds. Cambridge: Harvard University Press

Holland, D., \& Lachicotte, Jr., W. (2007). Vygotsky, mead, and the new sociocultural studies of identity. In H. Daniels, M. Cole, and J. V. Wertsch (Eds.), The Cambridge companion to Vygotsky (pp. 101-135). Cambridge: Cambridge University Press.

Izadinia, M. (2013). A review of research on student teachers' professional identity. British Educational Research Journal, 39(4), 694-713.

Jawitz, J. (2009). Academic identities and communities of practice in a professional discipline. Teaching in Higher Education 14 (3): 241-251.

Jenkins, R. (1996). Social identity. London: Routledge.

Johnson, K. E., \& Golombek, P. (2002). Teachers' narrative inquiry as professional development. New York: Cambridge University Press.

Johnson, K.E. (2007). The sociocultural turn and its challenges for second language teacher education. TESOL Quarterly, 40(1), 235-57.

Korhonen, V., \& Törmä, S. (2016). Engagement with a teaching career-how a group of Finnish university teachers experience teacher identity and professional growth. Journal of Further and Higher Education, 40(1), 65-82.

Kumaravadivelu, B. (2012). Language teacher education for a global society: A modular model for knowing, analyzing, recognizing, doing, and seeing. Abingdon: Routledge.

Liu, Y., \& Xu, Y. (2011). Inclusion or exclusion? A narrative inquiry of a language teacher's identity experience in the new work order of competing pedagogies. Teaching and Teacher Education, 27(3), 589-597.

Luebbers, J. B. (2010). How foreign language preservice teachers' development, identities, and commitments are shaped during teacher education. Unpublished PhD dissertation, The Ohio State University, Columbus, OH.

Lyons, N., \& LaBoskey, V. K. (Eds) (2002) Narrative inquiry in practice: advancing the knowledge of teaching. New York: Teachers College Press.

Maclean, R., \& White, S. (2007) Video reflection and the formation of teacher identity in a team of pre-service and experienced teachers. Reflective Practice, 8, 47-60.

Margo, R. (2014). Representation of the Ethiopian Multicultural Society in Secondary Teacher Education Curricula. Journal of Teacher Education for Sustainability, 16(1), 54-75.

Martel, J., \& Wang, A. (2015). Language teacher identity. In M. Bigelow C \& J. EnnserKananen (Eds.), The Routledge handbook of educational linguistics (pp. 289-300). New York: Routledge. 
McNaughton, S. M., \& Billot, J. (2016). Negotiating academic teacher identity shifts during higher education contextual change. Teaching in Higher Education, 21(6), 644-658.

Meijer, P. C., de Graaf, G., \& Meirink, J. (2011). Key experiences in student teachers' development. Teachers and Teaching: Theory and Practice, 17(1), 115-129.

Menard-Warwick, J. (2008). The cultural and intercultural identities of transnational English teachers: Two case studies from the Americas. TESOL Quarterly, 42(4), 617-640.

Menard-Warwick, J. (2011). Chilean English teacher identity and popular culture: three generations. International Journal of Bilingual Education and Bilingualism, 14(3), 261-277.

Miedema, S., \& Bertram-Troost, G. (2015). The Challenges of global citizenship for worldview education. The perspective of social sustainability. Journal of Teacher Education for Sustainability, 17(2), 44-52.

Miller, J. (2009). Teacher identity. In A. Burns and J. C. Richards (Eds.), The Cambridge guide to second language teacher education (pp. 172-181). New York: Cambridge University Press.

Morgan, B. (2004). Teacher identity as pedagogy: Towards a field-internal conceptualisation in bilingual and second language education. International Journal of Bilingual Education and Bilingualism, 7(2-3), 172-188.

Morgan, B., \& Clarke, M. (2011). Identity in second language teaching and learning. In E. Hinkel (Ed.), Handbook of research in second language teaching and learning (pp. 817-836). New York: Routledge.

Norton, B. (2000). Identity and language learning: Gender, ethnicity and educational change. Harlow, England: Pearson Education.

Park, G. (2012). I am never afraid of being recognized as an NNES: One teacher's journey in claiming and embracing her nonnative-speaker identity. TESOL Quarterly, 46(1), 127-151.

Putnam, R. T., \& Borko, H. (1997) Teacher learning: implications of new views of cognition. In B.J. Bidde, T.L. Good \& I.F. Goodson (Eds), International handbook of teachers and teaching (pp. 1223-1296). Dordrecht, The Netherlands, Kluwer Academic.

Raus, R. (2016). Modelling a learning journey towards teacher ecological self. Journal of Teacher Education for Sustainability, 18(2), 41-52.

Sarbin, T. (Ed.) (1986). Narrative psychology: the storied nature of human conduct. New York: Praeger.

Sen, A. (2006). Identity and violence: The illusion of destiny. New York: Allen Lake. Spradley, J. (1979). The ethnographic interview. New York: Holt, Rinehart \& Winston. Stanszus, L., Fischer, D., Böhme, T., Frank, P., Fritzsche, J., Geiger, S., Harfensteller, J., Grossman, P., \& Schrader, U. (2017). Education for Sustainable Consumption through Mindfulness Training: Development of a Consumption-Specific Intervention. Journal of teacher education for sustainability, 19(1), 5-21.

Taylor, C. (1989). Sources of the self. The making of the modern identity. Cambridge: Cambridge University Press.

Vygotsky, L. S. (1979). Consciousness as a problem in the psychology of behavior. Soviet psychology, 17(4), 3-35. 
Yi, L. (2009). Teachers' identities in personal narratives. In J. Lo Bianco, J. Orton, and G. Yihong (Eds.), China and English: Dilemmas of identity (pp. 255-267). Bristol, UK: Multilingual Matters.

Zeichner, K., \& Tabachnick, B. R. (1981). Are the effects of university teacher education washed out by school experiences? Journal of Teacher Education, 32(3), 7-11.

Correspondence concerning this paper should be addressed to Hussein Meihami, PhD Candidate in Applied Linguistics (TEFL), Department of Foreign Languages and Linguistics, Shiraz University, 71946-84695, Shiraz, Iran. Email: s.hmeihami@rose.shirazu.ac.ir 